\title{
A SEMI-AUTOMATED TOOL FOR REDUCING THE CREATION OF FALSE CLOSED DEPRESSIONS FROM A FILLED LIDAR-DERIVED DIGITAL ELEVATION MODEL
}

\author{
John Wall \\ Department of Marine, Earth \& Atmospheric Sciences, 2800 Faucette Drive, Room 1125 Jordan Hall Campus Box \\ 8208, NC State University, Raleigh, NC, 27695-8208, jwall@ncsu.edu
}

Daniel H. Doctor

U.S. Geological Survey, 12201 Sunrise ValleyDrive, Reston, VA, 20192, dhdoctor@usgs.gov

\section{Silvia Terziotti}

U. S. Geological Survey, 3916 Sunset Ridge Road, Raleigh, NC, 27607, seterzio@usgs.gov

\begin{abstract}
Closed depressions on the land surface can be identified by 'filling' a digital elevation model (DEM) and subtracting the filled model from the original DEM. However, automated methods suffer from artificial 'dams' where surface streams cross under bridges and through culverts. Removal of these false depressions from an elevation model is difficult due to the lack of bridge and culvert inventories; thus, another method is needed to breach these artificial dams. Here, we present a semiautomated workflow and toolbox to remove falsely detected closed depressions created by artificial dams in a DEM. The approach finds the intersections between transportation routes (e.g., roads) and streams, and then lowers the elevation surface across the roads to stream level allowing flow to be routed under the road. Once the surface is corrected to match the approximate location of the National Hydrologic Dataset stream lines, the procedure is repeated with sequentially smaller flow accumulation thresholds in order to generate stream lines with less contributing area within the watershed. Through multiple iterations, artificial depressions that may arise due to ephemeral flow paths can also be removed. Preliminary results reveal that this new technique provides significant improvements for flow routing across a DEM and minimizes artifacts within the elevation surface. Slight changes in the stream flow lines generally improve the quality of flow routes; however some artificial dams may persist. Problematic areas include extensive road ditches, particularly along divided highways, and where surface flow crosses beneath road intersections. Limitations do exist and the results partially depend on the quality of data being input. Of 166 manually identified culverts from a previous study by Doctor and Young in 2013, 125 are within $25 \mathrm{~m}$ of culverts identified by this tool. After three iterations, 1,735 culverts were identified and cataloged. The result is a reconditioned
\end{abstract}

elevation dataset, which retains the karst topography for further analysis, and a culvert catalog.

\section{Introduction}

The identification of closed depressions within a landscape is important for karst studies; however the automated creation of closed depression catalogs are hampered in urban locations. Automated depression delineation and cataloging methods have been discussed elsewhere (e.g., Lindsay and Creed, 2006; Zandbergen, 2010; Doctor and Young, 2013). Of these methods, the filling method (subtracting an initial digital elevation model (DEM) from the DEM with depressions filled to spill points) tends to be preferred due to the ease and speed by which a catalog can be generated. However, in populated areas simulated water flow tends to pond behind roads, railways, and other man-made surface features resulting in falsely detected closed depressions. These problems are especially acute when using highresolution topographic datasets such as Light Detection and Ranging (lidar), but are not unique to these DEMs. There are a number of methods to deal with these false depressions, but care has to be taken when working within karst terrain as these depressions are likely to be real and of interest to further research (Zandbergen, 2010; Lindsay and Creed, 2006).

Current means to remove topographic barriers use either manual or digital methods. Manual methods require the digitization of lines (here collectively referred to as 'culverts') representing underpasses beneath roads, driveways, railways, or other obstructions to actual stream flow using either aerial or field observations. As to be expected, these methods are very time consuming. Following the digital creation of a culvert inventory, this dataset is then used as input into a variety of techniques to 'cut' or 'burn' the culverts into the elevation data. This 
'burning' method normally uses the entire stream network to hydrologically condition the surface (e.g., Mitasova et al., 1999; Maidement, 2002; Tarbonton, 2012). However, these methods can be difficult to implement, or can create steep canyons in the hydrologically corrected elevation data potentially causing errors in further analysis, particularly when streams represented as vector lines do not accurately match the elevation surface. Current methods are too aggressive for karst terrain resulting in true depressions being scrubbed from the elevation dataset. For example, the optimized cut and fill tool (Jackson, 2013) would result in the removal of true depressions. Additionally, other tools such as those developed by Poppenga et al. (2010) require thresholds (i.e. area and depth) be set which could result in smaller, artificial depressions being missed.

The goal of this study was to develop an ArcGIS toolbox to identify potential culvert locations which could then be enforced into the elevation data, thereby removing false closed depressions within karst terrain. This is done by finding the intersection of transportation routes and stream lines which are then buffered and used to lower the elevation across the man-made topography. This method minimizes the extent of DEM modification in order to retain the karst depressions. A semi-automated approach is taken with user-provided data and thresholds.

\section{Study area and previous work}

The study area is the Boyce 7.5-minute quadrangle predominantly covering Clarke County with smaller portions of Warren and Fredrick Counties in Virginia (Figure 1). The region spans roughly $150 \mathrm{~km}^{2}$. Located within an extensive karst region of the Great Valley physiographic province of the Appalachian mountain range, the Boyce quadrangle covers part of the Shenandoah River drainage basin.

Details on the geology of the quadrangle can be found in Edmundson and Nunan (1973). Karstification in the study area has resulted in a mature dissected karst surface of moderate to low relief, with $90 \mathrm{~m}$ total elevation range and a mean elevation of $180 \mathrm{~m}$ above sea level. Sinkholes and other karstic depressions generally occur as a result of cover-collapse or suffosion processes within the residuum overlying the carbonate bedrock;

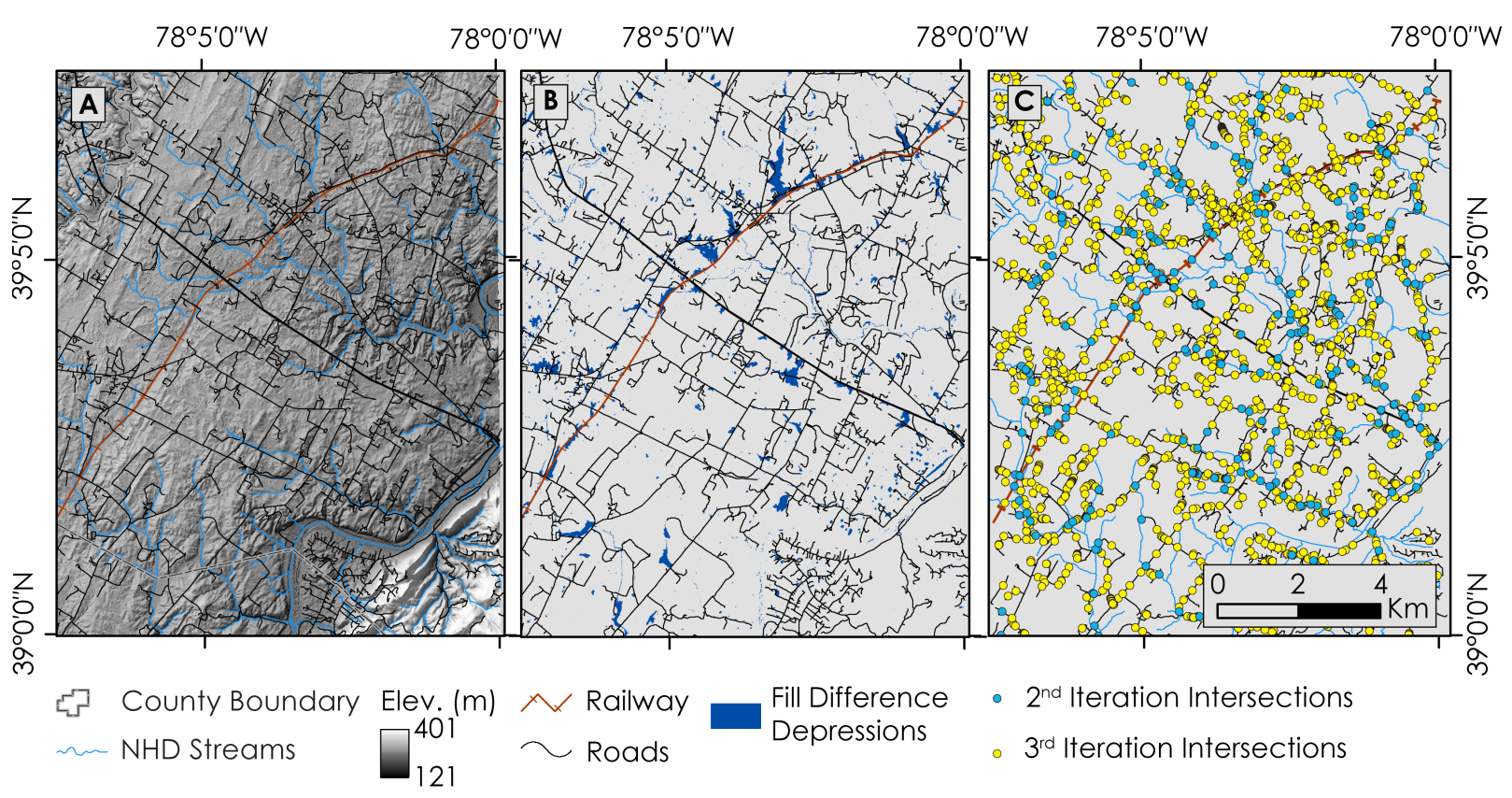

Figure 1. (A) Digital Elevation Model of the Boyce 7.5-minute quadrangle with a draped hillshade. Intersections between NHD Streams, railways and roads. (B) An initial fill difference raster map illustrates ponding behind artificial dams created by railways and roads. The fill difference raster is created by subtracting the initial DEM from the filled DEM. (C) The second and third iterations of intersections identified by the Cutter tool are shown. Note the increase in intersections found between both of these iterations, which directly corresponds to the different flow accumulation thresholds $\left(400,000 \mathrm{~m}^{2}\right.$ and $\left.10,000 \mathrm{~m}^{2}\right)$ used. 
the thickness of residuum varies between zero and ten meters.

Doctor and Young (2013) presented an evaluation of an automated workflow for identifying closed depressions in the Boyce quadrangle using a simple fill-difference method. This method uses the difference between a 'filled' DEM raster and the original raster, and was compared to manually-delineated closed depressions. They concluded that the primary hindrance to a fullyautomated process for identifying closed depressions was the presence of artificial 'dams' in the elevation surface where streams pass beneath transportation routes. For that study, stream underpasses, usually in the form of culverts, were identified from aerial imagery and field work, and were manually added as an input layer used to recondition the original DEM allowing streams to flow through elevation obstructions such as those created by transportation routes. Although this approach was effective, it was tedious and was not successful in identifying all possible culverts within the quadrangle thereby impacting the closed depression catalog count and morphometrics. Thus, a new automated method to identify stream underpasses was deemed necessary.

\section{Methods}

The method presented here for reducing the creation of false closed depressions was developed using ArcGIS tools. For this work, ArcGIS 10.2.2 was used, but the models should work with any 10.X version of ArcGIS. Additionally, a license for the Spatial Analyst Tools is necessary.

Three vector datasets were acquired covering streams, railways and road networks along with a high-resolution lidar raster data set. Stream data were acquired from the United States Geological Survey's (USGS) National Hydrologic Dataset (NHD). Railways and roads were acquired from the USGS National Map. All vector datasets were digitized at the 1:24,000 scale, which is much coarser resolution than the lidar data. This resulted in the need to manually correct the railway shapefile (Figure 2 ). The resulting corrected vector data was used as input into the tools. The lidar dataset was acquired between 1 March and 9 March 2011. Acquisition took place during leaf-off conditions and after snow cover melted. The vertical RMSE was $9.0 \mathrm{~cm}$ while the point spacing was $1.0 \mathrm{~m}$.

The Hydrocutter toolbox contains two tools: Hydro and Cutter. Together, these tools can be run iteratively in a semi-automated way employing user thresholds. Hydro simply implements a stream definition method as determined using the Fill, Flow Direction, and Flow Accumu- lation tools provided by ESRI within the Spatial Analyst à Hydrology toolbox. The result of the Hydro tool is a vector dataset which can be used as an input into Cutter. Cutter topographically enforces culverts where streams pass beneath topographic highs, generally along transportation routes, thereby providing a flow path across the artificial obstruction in the DEM and reducing false closed depressions.

The Processing Extent, Snap Raster, and Cell Size are all set to the DEM provided by the user within the tool environments automatically so that they do not need to be set by the end-user.

The workflow for the Cutter tool is outlined by Figure 3 and described in detail here. Transportation vector datasets are intersected with an initial NHD stream vector dataset. This results in two point datasets (one for railways and one for roads, respectively) which are then merged into a single point dataset representing all intersections with streams (i.e. culverts). These culverts are then buffered by a user-defined value which should span the widest railway or road. For this study, a $25 \mathrm{~m}$ buffer diameter around each point was used. The circular buffer polygons are then used to clip the stream vector line to provide stream segments where the streams cross the transportation routes. A Zonal Fill tool is then used to find the minimum elevation along the clipped vector segments (ESRI, 2012). This results in a raster layer which

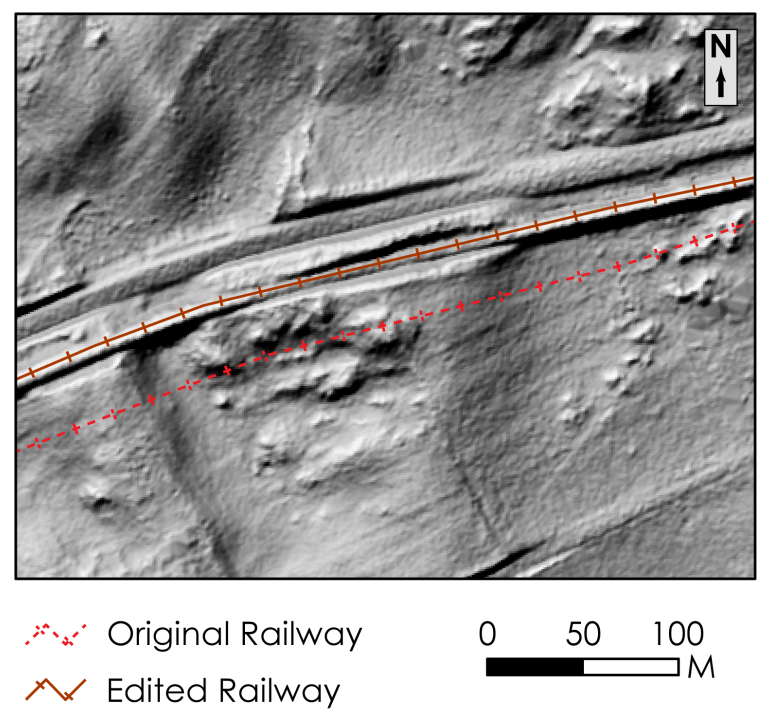

Figure 2. Data quality is important to consider when running Hydrocutter toolbox. Note the issues with the railway presented here. The initial railway data (dashed red line) is offset from the edited railway (dark brown solid line). 


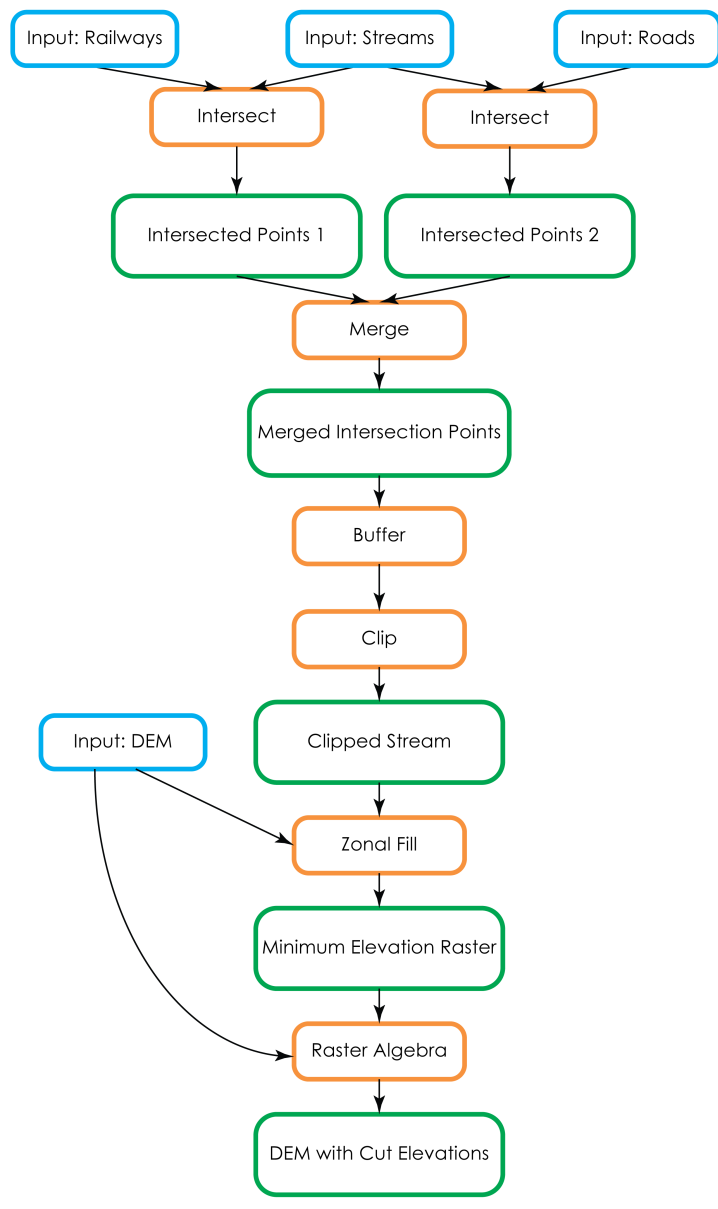

Figure 3. Work flow of the Cutter tool within the Hydrocutter toolbox.

is used to enforce this minimum elevation value into the DEM thereby hydrologically conditioning it.

This conditioned DEM is used as input into the Hydro tool. The only additional information that must be provided when running the Hydro tool is a threshold value for the flow accumulation. For this study area, a flow accumulation value of $400,000 \mathrm{~m}^{2}$ was found to reasonably approximate the lengths of the NHD stream vector lines and was therefore used for the initial iteration of this tool.

The Hydrocutter toolbox was run on the lidar data covering the Boyce quadrangle. The initial iteration of the Cutter tool used the NHD streams and edited roads and railway data as input. The resulting DEM was then used as input into the Hydro tool and a flow accumulation threshold of $400,000 \mathrm{~m}^{2}$ was used to approximate the surface flow accumulation of the NHD streams.
A second hydrologic conditioning iteration was carried out using newly defined $400,000 \mathrm{~m}^{2}$ flow accumulation streams and transportation routes, and then the Hydro tool was repeated the using a flow accumulation of $10,000 \mathrm{~m}^{2}$. After the DEM had been reconditioned to account for intersections between the stream lines of $10,000 \mathrm{~m}^{2}$ flow accumulation, stream lines at $2,000 \mathrm{~m}^{2}$ flow accumulation were generated for visual comparison and validation.

Given the different approaches, the closed depressions catalogs identified after running the Hydrocutter toolbox described here and those of Doctor and Young (2013) are not directly comparable; however, here we heuristically compare these datasets.

\section{Results}

Using the Hydrocutter toolbox approximately 14 times as many culverts and stream intersections with transportation routes were found as those identified manually within the Boyce quadrangle. Of these, $75 \%$ were coincident with culvert lines from Doctor and Young (2013) within a $25 \mathrm{~m}$ buffer zone.

The 2,000 $\mathrm{m}^{2}$ flow accumulation stream lines often represent flow routes across the DEM surface that do not have any obvious geomorphic expression of surface runoff, such as channels, swales, gullies, etc. Thus, stream lines having flow accumulation values less than 10,000 $\mathrm{m}^{2}$ are not used here to define additional culverts. As a result, the $10,000 \mathrm{~m}^{2}$ flow accumulation stream lines identified the majority of topographically evident stream channels as well as creating an inventory of potential culverts (Figure 4).

Doctor and Young (2013) manually identified 166 culverts of which 106 were verified by aerial imagery or field checking. Of the manually identified culverts 125 are within $25 \mathrm{~m}$ of the Hydrocutter culverts, 80 of these were verified. The first pass of the Hydrocutter toolbox found 260 intersections between the NHD stream vector lines and the transportation vector lines; these intersections were indicative of possible stream culverts. These culverts were burned into the original DEM, and used to generate a new stream vector line dataset that was more representative of the actual lidar-derived elevation model. The next iteration used lidar generated stream lines with a flow accumulation of $400,000 \mathrm{~m}^{2}$ thus mimicking the original NHD vector stream lines and identified 272 culverts. The final iteration, using a flow accumulation of $10,000 \mathrm{~m}$, identified 1,735 culverts. 

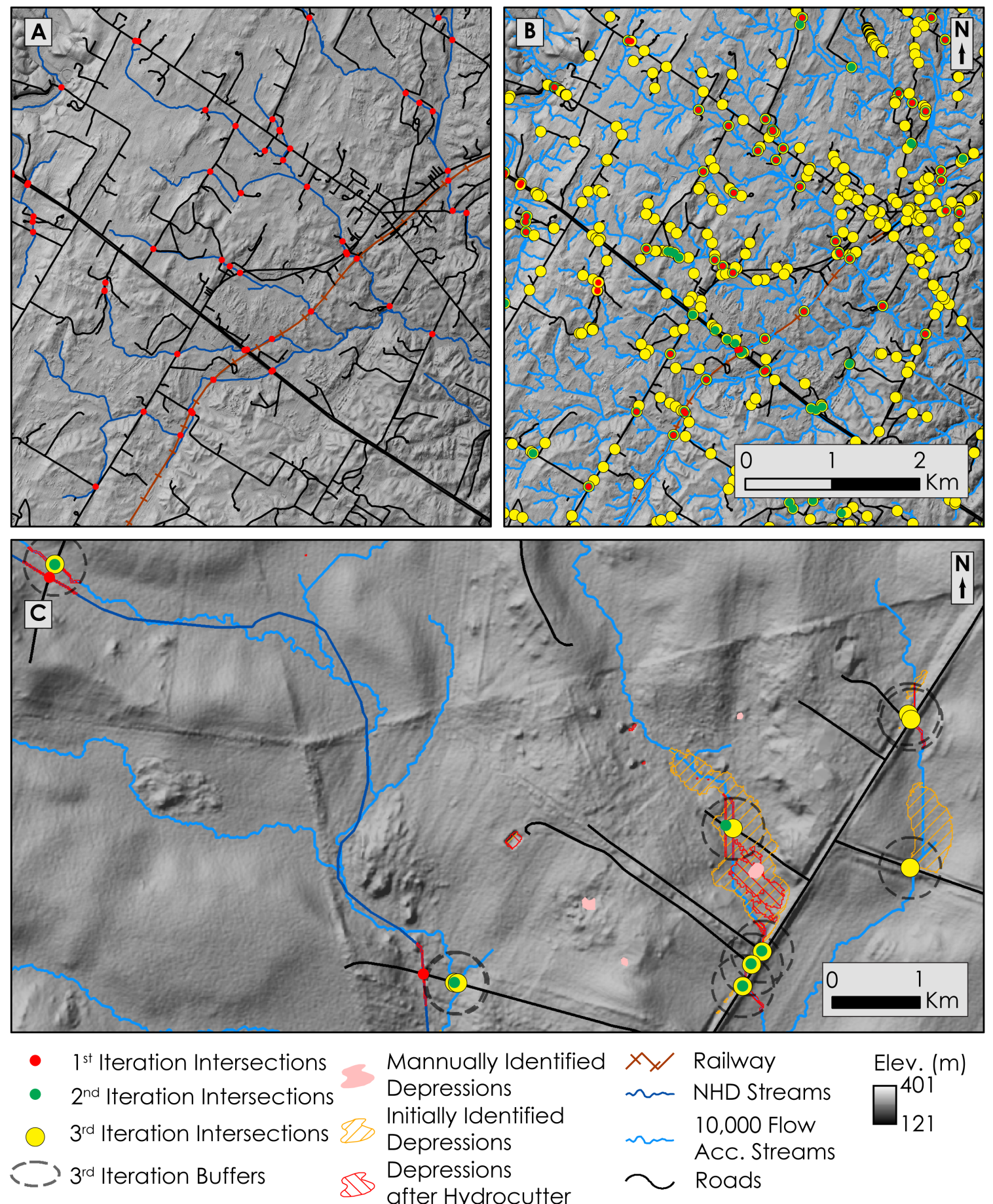
Mannually Identified
Depressions
Initially Identified
Depressions
$\$ \begin{aligned} & \text { Depressions } \\ & \text { after Hydrocutter }\end{aligned}$

$x$ Railway

n NHD Streams

10,000 Flow

Elev. $(m)$

Acc. Streams

$\square_{121}^{401}$

$\frown$ Roads

Figure 4. (A) Red points indicate the initial intersections found between NHD stream data with roads and railway data. These are compared to (B) green and yellow points which are the intersections found between the 400,000 $\mathrm{m}^{2}$ and 10,000 $\mathrm{m}^{2}$ stream lines respectively and transportation routes. As indicated by panels $A$ and $B$, the stream lines with the lower flow accumulation extend further upstream and therefore intersect a greater number of roads. (C) A detail of these differences is illustrated between initial intersections and subsequent iterations of the Hydrocutter tool resulting in differences of stream dataset quality highlighted particularly in the left half of the panel. 


\section{Conclusions}

The Hydrocutter toolbox provides two products useful in karst studies. The first is a hydrologically conditioned DEM by removing obstructions to flow routing that cause false closed depressions resulting from the impoundment of water behind man-made features such as roads. The second is an inventory of potential culverts which is not only useful to karst studies, but the broader geologic, hydrologic, and environmental management communities.

Nevertheless, there are several known issues and pieces of cautionary advice that come with using this tool. First, the user-defined buffer distance around intersections needs to be large enough to allow impoundments to be breached. This can be problematic when road widths are variable and span a greater width than the buffer distance used to define the 'cutting' of culverts. Second, in the Boyce quadrangle a flow accumulation of $10,000 \mathrm{~m}^{2}$ was determined as reasonable to represent surface water flow routes when compared to the topographic expression of the surface hydrology; however, this is not a constant value, meaning that a user should determine a reasonable flow accumulation value empirically for their study area by examining the correspondence between the elevation model and the stream lines generated. Third, errors due to poor vector data quality compared to the lidar data can be propagated through the analysis. Therefore, high accuracy of the vector data used as the initial inputs to the process is important. If good vector datasets are unavailable, manual editing to $1: 24,000$ scale vector data to match the lidar elevation model might be necessary, as was done here. Fourth, some re-routing of stream lines can occur between iterations of the Hydrocutter tools. This is localized to areas within or near the buffer zones of intersections (Figure 4).

The process outlined here generally improves the overall representation of flow across the DEM. It is only problematic in areas where the initial road or NHD stream data is poor. Thus, as with many tools, the quality of the data being input into the tool is inherently representative of the data quality coming out of the tool.

Although further quantitative comparison is necessary, the Hydrocutter toolbox is better at breaching man-made impoundments while preserving the natural closed depression landscape within karst terrain (Figure 5). This is vital to creating closed depression catalogs generated from lidar datasets rather than statewide inventories which adequately represent the closed depression population while minimizing false detections (Wall \& Bohenstiehl, 2014).

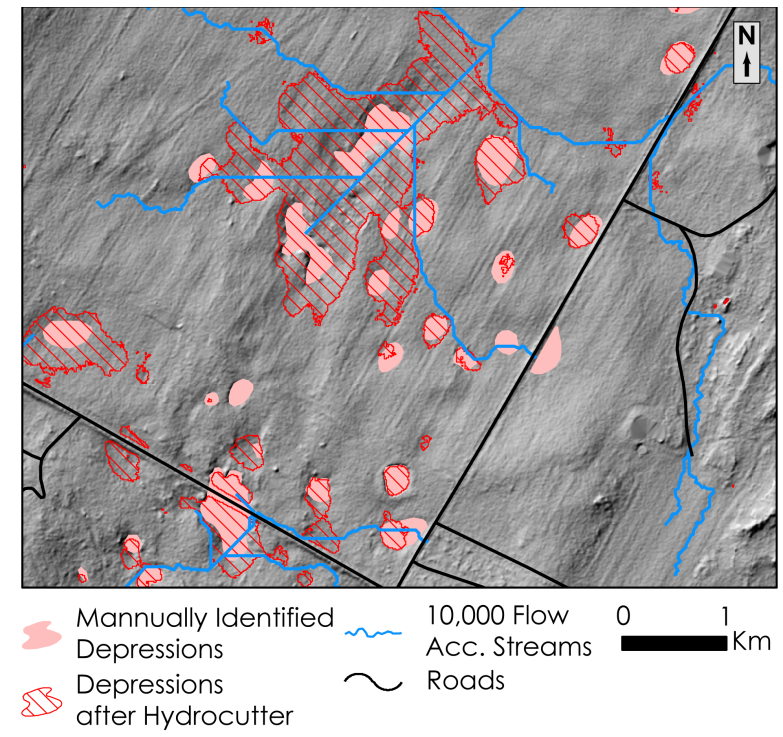

Figure 5. Depressions identified by Hydrocutter are compared to manually identified depressions. Note that some of the manually identified closed depressions are grouped into one closed depression using the results of Hydrocutter suggesting a coalescence of closed depressions which are not easily identified by manual interpretation.

A possible future refinement of the toolbox would be to improve the manner in which the location of a stream pathway is delineated across an impoundment. Using the current Cutter tool, the pathway follows the pre-existing stream line that crosses an obstruction. If the stream vector is not in the correct location (i.e. where a culvert or underpass is), then errors may result which could be propagated through the analysis. Clipped streams segments may not fully connect the actual stream channels in the lidar surface. Figure 6 illustrates a possible solution which would employ a least-cost path approach within the buffer zone of intersection to optimize the likelihood of connecting the lowest point on either side of the obstruction (Poppenga et al., 2010).

Future work will focus on implementing a hybrid method between the Cutter tool and least cost path technique. This will allow for more accurate connections between low points within the buffer zone. Ideally, this will be more representative of stream flow routes and culvert locations. It will have an added benefit of further reducing false closed depressions. 


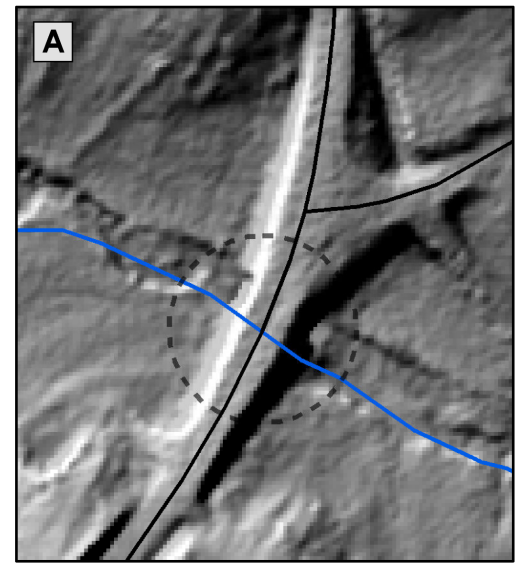

- $3^{\text {rd }}$ Iteration Buffers

NHD Streams

$\frown$ Roads

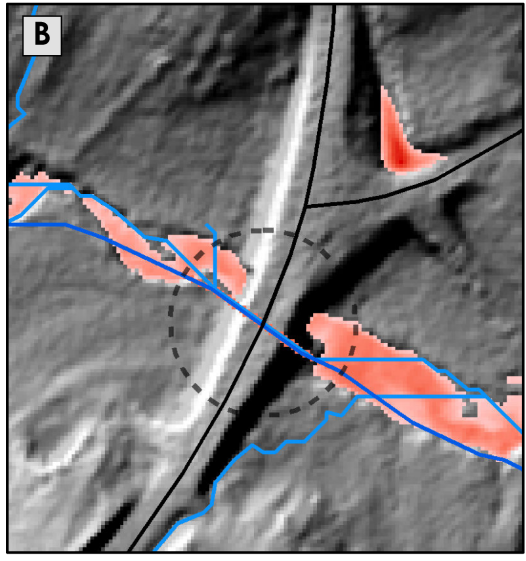

10,000 Flow Fill Diff. (m) Acc. Streams

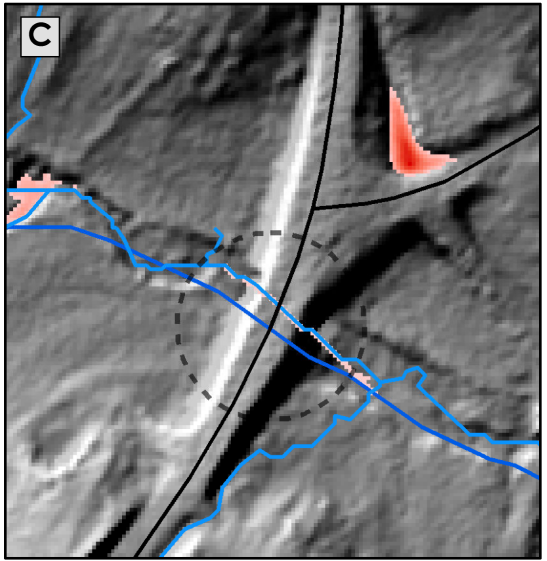

Path Streams
Least Cost 0

50 0.18

Figure 6. Future development for this toolbox is illustrated by (A) The original elevation surface shown with the NHD flow line and road intersection, (B) grid cells matching the NHD were recalculated with the minimum elevation value within the buffer zone to create hydrologic connectivity. The red areas indicate false depressions that remain, (C) The least cost path through the buffer zone is used to identify the cells to calculate as the flow path through the topographic high.

\section{Acknowledgments and Disclaimer}

We wish to thank John Young (USGS), Alan H. Rea (USGS), and Brian Bruckno (Virginia Dept. of Transportation) for helpful reviews. Although these data have been processed successfully on a computer system at the U.S. Geological Survey (USGS), no warranty expressed or implied is made regarding the display or utility of the data on any other system or for general or scientific purposes, nor shall the act of distribution constitute any such warranty. The USGS or the U.S. Government shall not be held liable for improper or incorrect use of the data described and/or contained herein. Any use of trade, firm, or product names is for descriptive purposes only and does not imply endorsement by the U.S. Government.

\section{References}

Doctor DH, Young JA. 2013. An evaluation of automated GIS tools for delineating karst sinkholes and closed depressions from 1-meter lidar-derived digital elevation data. In: Land L, Doctor DH, Stephenson JB, editors. Sinkholes and the Engineering and Environmental Impacts of Karst: Proceedings of the Thirteenth Multidisciplinary Conference, May 6-10, Carlsbad, New Mexico: NCKRI Symposium 2. Carlsbad (NM). National Cave and Karst Research Institute, p. 449-458
Edmundson RS, Nunan WE. 1973. Geology of the Berryville, Stephenson and Boyce Quadrangles, Virginia. Virginia Division of Mineral Resources Report of Investigations 34, Charlottesville, Virginia. 112 pp., 3 plates, 1:24,000 scale.

ESRI. 2012. ArcGIS Help 10.1 - Zonal Fill (Spatial Analyst). Available online at http://resources.arcgis.com/en/help/main/10.1/index.html\#/Zonal_ Fill/009z000000w3000000/

Jackson S. 2013. Optimized Pit Removal V1.5.1 Tutorial. Center for Research in Water Resources University of Texas at Austin. Available online at http://tools.crwr.utexas.edu/OptimizedPitRemoval/CRWR\%20Tools\%20Optimized\%20Pit\%20 Removal.html (accessed March 16, 2015).

Lindsay JB, Creed IF. 2006. Distinguishing actual and artefact depressions in digital elevation data. Computers \& Geosciences 32: 1192-1204.

Maidment DR. 2002. Arc Hydro: GIS for water resources. Esri Press.

Mitasova H, Mitas L, Brown WM, \& Johnston DM. 1999. Terrain modeling and soil erosion simulations for Fort Hood and Fort Polk test areas. Geographic Modeling and Systems Laboratory, University of Illinois at Urbana-Champaign.

Poppenga SK, Worstell BB, Stoker JM, Greenlee SK. 2010. Using selective drainage methods to extract 
continuous surface flow from 1-meter lidar-derived digital elevation data. U.S. Geological Survey Scientific Investigations Report 2010-5059, 12 p.

Tarboton DG. 2012. Terrain analysis using digital elevation models (TauDEM). Logan, UT. Available online at http://hydrology.uwrl.usu.edu/taudem/ taudem5.0/index.html (accessed March 16, 2015).

Wall J, Bohnenstiehl DR. 2014. Power-law relationship of sinkholes and depressions within karst geology 63rd Annual Meeting Southeastern Section of the Geological Society of America, Blacksburg, Virginia, 10-11 April.

Zandbergen PA. 2010. Accuracy considerations in the analysis of depressions in medium-resolution $\mathrm{Li}$ dar DEMs. GIScience \& Remote Sensing 47 (2): 187-207. 